\title{
6.2 Ограничительные мероприятия при эпидемиях и особенности течения карантина при COVID-19
}

История использования карантина - как ограничительной меры при эпидемических вспышках инфекционных заболеваний является увлекательным и позволяет понять то, как этот метод использовался в прошлом и почему он не потерял своей актуальности сегодня. На протяжении веков, со времен чумы до первых пандемий XXI века, ограничительные меры были основным способом снижения контакта между больными и людьми с риском заражения. В отсутствие необходимых фармацевтических средств, использование таких мер помогало сдержать инфекцию, задержать распространение болезни, предотвратить хаос в обществе и высокую смертность, поддерживая нормальную инфраструктуру.

Организованные мероприятия по борьбе с инфекционными заболеваниями впервые начали проводится во время эпидемии чумы в 1347-1352 годах. Первоначально чума распространялась моряками, крысами и грузом, прибывающим на Сицилию из восточного Средиземноморья. Она быстро распространялась по всей Италии, уничтожая население крупных городов и государств, таких как Флоренция, Венеция и Генуя. Чума затем переместилась из портов Италии в порты Франции и Испании. Из северо-восточной Италии чума пересекла Альпы и перенеслась в Австрию и Центральную Европу. К концу четырнадцатого века эпидемия ослабла, но не исчезла. Отмечались вспышки легочной формы чумы в разных городах в течение следующих 350 лет [287,288,291,292,293].

Медицина была бессильна против чумы. Единственным известным на тот период способом избежать заражения являлось недопущение контакта с инфицированными людьми и загрязненными предметами. В связи с этим, некоторые города не позволяли входить в их города, торговцам и группам меньшинств, таким как евреи и люди с проказой. Санитарный кордон не должен был быть сломлен даже под страхом смерти, его охраняли вооруженные военные в точках доступа к городам. Реализация этих мер потребовала быстрых и 
решительных действий со стороны властей, включая оперативную мобилизацию городских полицейских сил. Жесткое подразделение на здоровых и инфицированных людей было первоначально достигнуто посредством использования временных лагерей [286,289, 294].

Карантин был впервые введен в 1377 году в Дубровнике на побережье Далмации в Хорватии, а первый постоянный чумный госпиталь (или "лазаретто") был открыт в Венецианской республике в 1423 году на небольшом острове Санта-Мария ди Назарет. "Лазаретто" обычно упоминается как "назаретум" или "Лазаретум" из-за сходства этого слова с библейским именем Лазарь. В 1467 году венецианскую систему приняла Генуя, а в 1476 году в Марселе, Франции больница для лечения проказы была преобразована в такой лазарет. Лазареты были расположены достаточно далеко от жилых районов города, чтобы ограничить распространение болезни, но достаточно близко, чтобы транспортировать больных. По возможности лазареты располагались так, чтобы определенный барьер, такой как море или река, отделял их от города. В портах лазареты состояли из зданий, используемых для изоляции пассажиров и членов экипажа, которые имели подозрение на чуму. Товары с судов выгружались в обозначенные здания. Процедуры для так называемой «чистки» различных продуктов назначались в строго определенное время. Такие материалы как шерсть, пряжа, ткань, кожа, парики и одеяла считались наиболее опасными для передачи заболевания. Обработка товаров состояла из постоянной вентиляции, воск и губки после обработки погружались в проточную воду на 48 часов [290,294,295,296].

Неизвестно почему именно показатель 40 дней был выбран в качестве длительности времени для изоляции, необходимой для избежания заражения. Возможно, такая концепция была связана с теорией Гиппократа относительно инфекционных заболеваний. Другая теория заключалась в том, что количество дней было связано с теорией чисел Пифагора, согласно которой число 4 имело особое значение. Сорок дней также были периодом библейского страдания Иисуса в пустыне. Считалось, что сорок дней представляют собой время, 
необходимое для рассеивания ядовитых веществ из тел людей и товаров через систему изоляции, фумигации и дезинфекции. В последующие века система изоляции была значительно улучшена.

Первые английские правила карантина, разработанные в 1663 году предусматривали заключение (в устье реки Темза) судов с подозреваемыми на заражение чумой пассажиров и экипаж. В 1683 году в Марселе новые законы требовали, чтобы все лица с подозрением на чуму были помещены на карантин и прошли дезинфекцию. В портах Северной Америки карантин был введен в течение того же десятилетия, когда предпринимались попытки контроля желтой лихорадки, которая впервые появилась в Нью Йорке и Бостоне в 1688 и 1691 годах. В некоторых колониях страх вспышек оспы, совпавший с прибытием судов, побудил органы здравоохранения ввести обязательную домашнюю изоляцию лиц с оспой, хотя для защиты от этой болезни использовалась другая, противоречивая на тот период стратегия - вакцинация. В США карантинное законодательство, которое до 1796 года было ответственностью штатов, осуществлялось в портовых городах, которым угрожала желтая лихорадка из Западной Индии. В 1720 году во время эпидемии чумы, вспыхнувшей в Марселе и разоренном Средиземноморском побережье Франции, вызвало большие опасения в Англии. В Англии действовал Закон о карантине с 1710 года, был возобновлен в 1721, 1733 и в 1743 годах во время катастрофической эпидемии в Мессине, Сицилия. Система активного наблюдения была создана в основных Левантинских городах. Сеть, образованная консулами разных стран, соединила великие средиземноморские порты Западной Европы [297,298,299,300].

К XVIII веку появление желтой лихорадки в средиземноморских портах Франции, Испании и Италии вынудило правительство ввести правила, связанные с использованием карантина. В XIX веке появилась еще более страшная угроза холера. Холера возникла в период нарастания процесса глобализации, вызванной технологическими изменениями в транспортной системе, резким сокращением времени в пути на пароходах и через железные дороги, а также ростом торговли. Холера или «азиатская болезнь», достигла Европу в 1830 году и Соединенных 
Штатов в 1832 году ужаснув все население. Несмотря на прогресс в отношении определения причины и передачи холеры, у медицины того времени не было эффективных способов для борьбы с этим заболеванием [301,302,303].

Во время первой волны вспышек холеры стратегии, принятые должностными лицами здравоохранения, были в основном такими же как против чумы. Строительство новых лазаретов было запланировано в западных портах. Была создана обширная структура около города Бордо во Франции. В европейских портах был запрещен вход для кораблей, если у них были «нечистые лицензии», то есть если суда прибывали из районов, где бушевала холера. В городах власти использовали социальные вмешательства и традиционные инструменты для профилактики инфекционных заболеваний того времени. Например, путешественники, которые имели контакт с инфицированными или прибывшие из мест, где была эпидемия холеры, помещались на карантин, а больные принудительно в лазарет. Таким образом, местные власти пытались держать опасные слои общества вдали от города. В 1836 году в Неаполе чиновники здравоохранения препятствовали свободному движению проституток и нищих, которые считались носителями инфекции и, таким образом, представляли опасность для здоровья городского населения. Эти мероприятия также включали полномочия для вмешательства в жизнь населения в обычное время, что вызывало широко распространенный страх и обиду граждан.

Группа людей, которые не верили в контагиозность холеры, оспаривали карантин и утверждали, что данная практика была пережитком прошлого, бесполезной и вредной для торговли. Они жаловались, что свободному движению путешественников мешали санитарные кордоны и контроль на пограничных переходах, которые включали фумигацию и дезинфекцию одежды. Кроме того, карантин внушил людям ложное чувство безопасности, которое было опасным для общественного здравоохранения, потому что оно отвлекало людей от принятия правильных мер предосторожности. Международному сотрудничеству и координации препятствовало отсутствие согласия 
относительно использование карантина. Дискуссии среди ученых и деятелей сферы здравоохранения, тянулись на протяжении десятилетий, как показано в дебатах во время международных санитарных конференций. В особенности после открытия в 1869 году Суэцкого канала, который воспринимался многими как ворота для ввоза болезней из Восточных стран. Несмотря на распространенные сомнения относительно эффективности карантина, местные власти неохотно отказывались от традиционных стратегий, которые обеспечивали сохранность от паники в обществе, которая во время серьезной эпидемии могла порождать хаос и нарушать общественный порядок.

Поворотным моментом в истории карантина стало определение возбудителей большинства наиболее опасных эпидемических заболеваний на рубеже XIX и XX веков. Профилактика холеры, чумы и желтой лихорадки стала рассматриваться отдельно.

В 1911 году в одиннадцатом издании Британской энциклопедии подчеркивалось, что старая санитарно-профилактическая система задержания кораблей и людей стала делом прошлого. В то время борьба с инфекционными заболеваниями казалась выигранной, и старые профилактические практики остались лишь как архаичная научная ошибка. Никто не ожидал, что через несколько лет народы снова будут вынуждены принять чрезвычайные меры в связи с появлением новой серьезной угрозы для здоровья людей - пандемии гриппа 1918 года, которая в 1918 году поразила мир тремя волнами и осталась в истории как "испанка". В то время этиология этого заболевания была неизвестной. Большинство ученых считали, что возбудителем болезни была бактерия Haemophilus influenzae, идентифицированная в 1892 году немецким бактериологом Ричардом Пфайффер [304].

В 1918-1919 годах в мире, разделенном прошедшей войной, многосторонние системы эпидемиологического надзора за здоровьем, которые были тщательно сформированы в предыдущие десятилетия в Европе и Соединенных Штатах, не позволили контролировать пандемию гриппа. Родоначальник Всемирной организации здравоохранения - Международное 
бюро социальной гигиены, расположенное в Париже, не смогло сыграть никакой роли во время вспышки. В начале пандемии медицинские офицеры армии изолировали солдат с симптомами, но болезнь, которая была чрезвычайно контагиозной, стала быстро распространяться, заражая людей почти в каждой стране. Различные меры борьбы с пандемией были испробованы. Органы здравоохранения в крупных городах западного мира реализовывали целые ряды стратегий для сдерживания болезней, включая закрытие школ, церквей и театров, а также приостановку общественных собраний. В Париже спортивное мероприятие, в котором должна было принять участие 10000 молодых людей, было отложено. Йельский университет отменил все публичные встречи на кампусе, а некоторые церкви в Италии приостановили исповеди и похоронные церемонии. Врачи поощряли использование таких мер, как гигиена дыхания и социальное дистанцирование. Тем не менее, меры были приняты слишком поздно и в несогласованном порядке, особенно в пострадавших от войны районах, где вмешательства (например, ограничения на поездки и пограничный контроль) были непрактичными, в то время, как движение войск облегчало распространение вируса [305,306,307,308].

В Италии, в которой наряду с Португалией была самая высокая смертность в Европе, школы были закрыты сразу после первого случая необычно протекавшей тяжелой геморрагической пневмонии. Однако это решение о закрытии школ не было одновременно принято всеми органами здравоохранения и образования. Решения, принимаемые органами здравоохранения, часто казались сфокусированными больше на успокоение общественности за счет предпринимаемых усилий прекратить передачу вируса, а не для того чтобы фактически остановить передачу вируса. Меры, принятые во многих странах несоразмерно затрагивали различные этнические и маргинальные группы. В колониальных владениях, ограничения на поездки затронули местное население. Роль, которую играли СМИ, в оказании влияния на общественное мнение, стала увеличиваться со временем. Газеты заняли противоречивые позиции в отношении мер здравоохранения и способствовали распространению паники. 
Corriere della Sera, самая крупная и влиятельная газета Италии, была принуждена гражданскими властями прекратить сообщать о количестве смертей (150-180 смертей/день) в Милане, потому что сообщения вызвали большое беспокойство среди граждан. В охваченных войной странах цензура вызвала недостаток коммуникации и прозрачности в отношении процесса принятия решений, что приводило к путанице и неправильному принятию мер борьбы с болезнями и средств профилактики, таких как маски для лица (по иронии судьбы называемыми тогда «морды» на итальянском).

Когда новая созданная организация - Всемирная организация здравоохранения приняла ответственность за международные карантинные правила в 1948 году, практика и порядок карантина значительно различались в разных странах, и общая ситуация была запутанной. Действующие международные санитарные конвенции были составлены в разное время, каждая с отдельной целью. Ни одна концепция не была общепринятой, так как разные страны придерживались различных взглядов на проблему. Кроме того, с момента принятия конвенций условия изменились, следовательно, они не приняли во внимание новые доступные методы для борьбы с некоторыми из заболеваний, которые они охватывали, и при этом они не были созданы, чтобы иметь дело с значительно увеличенным объемом и скоростью международного трафика.

Во время I Всемирной ассамблеи здравоохранения (1948 год) был введен один общий код на основе современных эпидемиологических принципов для обеспечения стран одной международной концепцией, которая могла бы быть адаптирована к изменяющимся условиям без задержек из-за формальностей при каждом изменении подписей и ратификации. Положение о такой концепции карантина существует в Конституции Всемирной организации здравоохранения, которая в статье 21 утверждает, что Всемирная ассамблея здравоохранения имеет право принимать нормативные акты в отношении санитарных и карантинных требований и в статье 22 , которая гласит, что принятые правила вступают в силу для всех государств-членов. 
Международные санитарные правила (1951 года). В конечном итоге, до четвертой сессии Всемирной ассамблеи здравоохранения соглашение было достигнуто, хотя предварительная работа о возможности составления правила замены санитарных конвенций уже была предпринята в 1946-1948 годах. Правила были подписаны как Правила № 2 ВОЗ 25 мая 1951 года. Эти правила охватывали и все еще охватывают все виды международных перевозок - суда, самолеты, поезда и дорожные транспортные средства. Они имеют дело с санитарными мерами по борьбе с заболеваниями в морских портах и аэропортах открытыми для международного движения, включая меры, проводимые при прибытии и выезде, санитарные документы и санитарные сборы. Правила представляют собой «максимальные меры, применимые к международным перевозкам, которое государство может потребовать для защиты своей территории от карантинных заболеваний».

Международные медико-санитарные правила (1969 и 2005 годов). Международные санитарные правила были пересмотрены и приняты ВОЗ под новым названием Международных медико-санитарных правил в 1969 году. Количество заболеваний, охватываемых этими правилами, сократилось с шести до четырех (холера, чума, желтая лихорадка и оспа). Оспа была впоследствии исключена путем внесения поправок (1981год) после ее глобальной ликвидации. Столкнувшись с глобальными проблемами, вызванными новыми и возрождающимися инфекционными заболеваниями в конце XX и в начале XXI века ВОЗ выпустила полностью пересмотренный свод Международных медикосанитарных правил в 2005 году. Правила 2005 года открыли новый глобальный режим наблюдения за состоянием общественного здоровья, что требует от государств-членов незамедлительно уведомлять ВОЗ обо всех опасных ситуациях, которые могут представлять собой чрезвычайную ситуацию в области общественного здравоохранения, имеющую международное значение $[311,312]$.

Изоляция в строгом медицинском смысле была основным методом предотвращения распространения инфекции еще со времен Ветхого Завета, 
учитывая ограниченность знаний об этиологии различных инфекционных болезней и соответствующих лекарств для борьбы с инфекцией. Считалось, чтобы можно было избежать таких заболеваний, как проказа и чума, не допуская контакта между больными и здоровыми людьми. Практика обозначения хижин или деревень, в которых находили тяжелые инфекционные заболевания и которые следует избегать, присутствовали в культуре нескольких народов Африки, Азии и Европы. Зоны изоляции варьировались по географическим размерам от лагерей до отдельных домов. У всех было одинаковое общее представление о внешней изоляции пациентов от восприимчивых людей, живущих вне изоляционного блока и внутри него. Было трудно добиться эффективной изоляции в случаях, когда заболевания были эндемичными, но сравнительно легко, когда оно развивалось на судах, которые подходили к свободным от болезней портам. Таким образом, изоляция судов была более успешной мерой, чем изоляция инфицированных пациентов на суше.

Научная основа концепции изоляции была сформирована после появления теорий Пастера и Коха об инфекционных заболеваниях в конце XIX века. Однако задолго до этого выяснилось, что такие заболевания распространяются при контакте. Самые ранние европейские свидетельства были найдены в трудах об оспе и кори, написанных Джироламо Фракасторо из Вероны. В классической книге Фракасторо связывал эти заболевания с конкретными семенами, которые распространяют болезнь при непосредственном контакте человека с человеком через промежуточные объекты.

Во время второй пандемии в XX веке, пандемии «азиатского гриппа» 1957-1958 годов некоторые страны уже заранее приняли меры по борьбе с распространением болезни. Та инфекция протекала, как правило, слабее чем грипп 1918 года, и ситуация в мире значительно отличалась. Понимание гриппа значительно продвинулось: возбудитель был выявлен в 1933 году, вакцины для сезонных эпидемий были доступны, а антибиотики были доступны для лечения осложнений. К тому же, Всемирная организация здравоохранения осуществила глобальный эпидемиологический надзора за гриппом, который обеспечивал 
раннюю профилактику начиная с того момента как новый вирус гриппа (H2N2) начал распространяться в Китае в феврале 1957 года. Вакцины были разработаны в западных странах, но еще не были широко доступны когда пандемия начала распространяться одновременно с открытием школ в нескольких странах. Меры контроля (например, закрытие приютов и яслей, запреты на публичные собрания) использовались в странах по-разному. В лучшем случае, они просто откладывали появление болезни на несколько недель.

Этот сценарий повторился во время пандемии гриппа А (H3N2) 1968-1969 годов, которая стала третьей и самой легкой пандемией гриппа XX века. Вирус был впервые обнаружен в Гонконге в начале 1968 года и был привезен в США в сентябре 1968 года морскими пехотинцами, возвращавшимися из Вьетнама. Зимой 1968-1969 годов, вирус распространился по всему миру, методы борьбы были ограничены и не было никаких конкретных мер сдерживания [309, 310].

Новая глава в истории карантина началась в начале XXI века. Как традиционное вмешательство мера карантина была возрождена в ответ на глобальный кризис, вызванный появлением атипичной пневмонии, ставшей серьезной угрозой для общественного здравоохранения во всем мире. SARS, который возник в провинции Гуандун, Китай, в 2003 году, распространился по маршрутам воздушных перевозок и быстро стал глобальной угрозой из-за быстрой передачи и высокой смертности, а также из-за отсутствия эффективных противовирусных препаратов и вакцины. Однако по сравнению с гриппом и ОРВИ, у атипичная пневмония более менее контагиозной и имела более длительный инкубационный период, обеспечивая время для введения ряда мер сдерживания, которые работали достаточно неплохо. Выбор мер сдерживания варьировали в разных странах, наиболее сильно пострадавших от атипичной пневмонии (Китай, Гонконг; Сингапур, Канада). В Канаде органы здравоохранения просили лиц, которые могли подвергнуться контакту с SARS, принять добровольный карантин. В Китае полиция оцепляла здания, были организованы контрольно-пропускные пункты на дорогах и даже установленные веб-камеры в частных домах. Особенно сильным был контроль над людьми в 
низших социальных слоях населения. Правительственные структуры были уполномочены изолировать работников в пораженных инфекцией районах. Чиновники общественного здравоохранения в некоторых областях прибегали к принудительным полицейским мерам, используя законы с чрезвычайно суровыми наказаниями (включая смертную казнь), против тех, кто нарушал карантин. Как и в прошлом, принятые в некоторых странах меры способствовали дискриминации людей и некоторые общины подняли протесты на ограничения путешествий.

Историческая перспектива помогает понять в какой степени паника, связанная с социальными предрассудками, срывала усилия общественного здравоохранения по борьбе с распространением инфекционных заболеваний. Во время вспышек чумы и холеры страх перед дискриминацией, обязательным карантином и изоляцией привел наиболее уязвимые социальные меньшинства к побегу из очагов инфекции, что способствовало распространению болезни дальше и быстрее. Но в эпоху глобализации страх, тревога и паника, подкрепленные СМИ, может распространяться дальше и быстрее, играя большую роль, чем в прошлом. В таких условиях все население, а не только его отдельные группы подвергается риску быть притесненным. Перед лицом новых проблем в XXI веке из-за растущего риска возникновения и быстрого распространения инфекционных заболеваний, карантин и другие инструменты общественного здравоохранения остаются центральными для обеспечения сдерживания инфекции. Но эти меры по своей природе требуют тщательной подготовки, чтобы избежать предрассудков и нетерпимости со стороны общества. Общественное доверие должно быть достигнуто путем регулярной, прозрачной и комплексной коммуникации, которая позволяет достигнуть баланса между рисками и преимуществами подобных мер. В связи с этим планирование адекватных ограничительных мер требует учитывать ценные уроки прошлого.

Особенностью нынешней пандемии COVID-19 является то, что она влияет не только на физическое здоровье, но и на психическое благополучие населения. 
Несмотря на то, что слова «беспокойство», «страх» и «стресс» периодически звучат в СМИ, это не воспринимается как что-то специфическое. Однако, с психологической точки зрения, нынешняя ситуация является совершенно новым источником стресса для общества. Многие сравнивают пандемию со стихийным бедствием или войной, но в подобных обстоятельствах угрозу легко узнать, тогда как при пандемии «угроза» может исходить от человека, который просто стоит рядом. С ростом числа пострадавших, в стране ежедневно сообщается о новых выявленных случаях, что ведет к распространению паники и беспокойства в связи с неизвестным заболеванием.

Новый коронавирус - (SARS-Cov2), вызывающий развитие тяжелой вирусной пневмонии появился в Ухане, Китай, в декабре 2019 года. ВОЗ назвала еe “COVID-19” и в последствии объявила в мире пандемию этого заболевания 11 марта 2020 года. На сегодняшний день в мире практически не осталось стран, не сталкивавшихся с этим заболеванием. Китай был первой страной, которое ввело карантин в Ухане 23 января 2020 года, а затем и по всей стране. Китайские специалисты в области общественного здравоохранения первыми поняли, что болезнь вряд ли будет контролироваться без строгих ограничительных мероприятий.

Чтобы оценить эффективность карантина при COVID-19, проводились исследования, использовавшие метод математического моделирования развития эпидемий инфекционных заболеваний, который показывает, как быстро люди превращаются из подозреваемых в подверженных воздействию инфекции, далее в инфицированных, а затем в перенесших инфекцию или погибших от нее. Используя такую модель, китайские ученые показали, что строгие карантинные меры в Китае, такие как домашний карантин, ограничения дорожного движения, запреты на поездки, продление китайских новогодних каникул и внепланового отпуска значительно уменьшили передачу инфекции в обществе и были чрезвычайно успешными при контроле начальных этапов распространения эпидемии. Другое исследование с использованием похожей модели выявило, что карантинные меры являются более практичными, чем пограничный контроль и 
санитарные кордоны для уменьшения распространения COVID-19. При соблюдении $100 \%$ строгого карантина модель прогнозировала, что число случаев снизится на 89,7\%. Эта же группа ученых также показала, что размер эпидемии возможно было снизить с 87\%, на 100\% при соблюдении карантинных мер в самом начале эпидемии в провинции Хубэй, Китай. Хотя определить оптимальный показатель применения карантина в обществе невозможно, такие математические моделирования хорошо иллюстрируют вероятную эффективность недавнего массового карантина.

В упомянутом выше исследовании было также подтверждено, что в провинции Хубэй с задержкой введения карантина на одну неделю, число случаев увеличится на 10\%. Напротив, было подсчитано, что более раннее введение карантина на 1-2 недели, могло снизить скорость распространения инфекции на $25 \%$ и $57,3 \%$ соответственно. Используя метод моделирования было показано, что такая политика, как массовый карантин, строгое ограничение движения населения и крупномасштабный мониторинг подозреваемых в инфицировании оказали наиболее значимый эффект на уменьшение масштабов эпидемии. Задержка в реализации такой политики на 5 дней увеличила бы размер эпидемии в 3 раза.

В некоторых исследованиях были предложены и другие методы смягчения последствий эпидемии кроме карантина. Исследования Майера представили доказательства того, что для разрыва цепи передачи, ограничительные меры должны быть сосредоточены на восприимчивой популяции и побудить поведенческие изменения в них. Hellewell и соавт. обнаружили, что отслеживание контактов и их изоляция являются достаточными для того, чтобы управлять вспышкой COVID-19 в течение 3 месяцев. При этом все контактировавшие должны быть изолированы, а различные сценарии подробно рассмотрены. На основании вышеизложенного, большинство исследований подтвердили выраженный положительный эффект от внедрения массового карантина и ограничения движения в Китае во время эпидемии COVID-19. 
Основными рисками психического здоровья людей в обществе являются следующее: неопределенный инкубационный период COVID-19 и его бессимптомное течение с возможной передачей окружающим, отчеты или новости в СМИ о нехватке медицинского персонала, больничных коек и аппаратов ИВЛ, широкомасштабные карантинные меры в крупных городах, ограничивающие движение и общение людей, первоначальное преуменьшение государством серьезности эпидемий, что привело к общественному недоверию.

В США был проведен опрос среди населения в начале пандемии, когда было зарегистрировано всего 5 случаев заражения коронавирусом. Анкетирование показало, что $37 \%$ респондентов были действительно обеспокоены распространением коронавируса в стране, 54\% не было уверено, что государство сможет его контролировать. Повторный опрос через несколько дней, показал, что 66\% опрошенных считали коронавирус реальной угрозой, $56 \%$ были обеспокоены его распространением, а 26\% считали, что государство принимает недостаточно мер по его сдерживанию.

Страх, который был вызван тяжелом течении заболевания, высокой смертностью, ограничительными мерами, юридическими наказаниями, недоверием к чиновникам, не справившимися с ситуацией и переполненные недостоверной информацией медиа-пространства - все это стало отрицательно сказывалось на психическом состояние людей. Страх перед неизведанным и недостаток знаний, как правило, компенсируется появлением слухов, домыслов, ложных новостей и теорий заговора, что в современном мире уже начали называть дезинфодемией. В эпохе интернета и социальных сетей информация стала распространяться гораздо быстрее чем сам вирус. Коллективное предубеждения посеяло зерно страха, предрассудков и ксенофобии.

В прошлом было принято ассоциировать вирусные заболевания с регионами, где были обнаружены первые их вспышки. В 2015 году ВОЗ даже разработали рекомендации с целью предотвратить подобные ассоциации, так как они приводят к негативным последствиям в виде страха, гнева и неприязни, направленных на эти регионы и население проживающее в них. Тем не менее, 
вспышка COVID-19 во всех СМИ связывалась с Китаем, что привело к тому, что люди азиатского происхождения стали подвергаться социальному неприятию.

Выделяют несколько групп населения, которые наиболее уязвимы к неблагоприятному психологическому влиянию пандемии. Среди них, в первую очередь, это лица, зараженные COVID-19. Это обусловлено тем, что сам факт наличия этого заболевания значительно влияет на психоэмоциональное состояние человека. Усугубляют состояние такие факторы как ограничение контакта с близкими и изоляция. Они могут вызывать аффективные реакции в ответ на стресс с депрессивным или тревожным настроением, в отдельных случаях даже склонность к суициду. Тяжелые симптомы заболевания и побочные эффекты лекарственных средств усиливают это состояние. Было описано много клинических случаев, когда коронавирусная инфекция вызывала бредовые состояния или психоз.

Следующей группой являются лица, находящиеся в изоляции. Влияние социальной изоляции на уязвимые группы населения, такие как пожилые люди и дети, достаточно хорошо известны. Так, показатели травматического стресса у детей, помещенных на карантин во время вспышки атипичной пневмонии 2003 года, были в 4 раза выше обычных показателей. Также, социальный опрос, проведенный в Китае показал, что уровень тревоги у людей, находившихся на 14-дневном карантине положительно коррелировал с показателем стресса и отрицательно коррелировал с качеством сна и уровнем социальной поддержки.

К факторам риска развития психических расстройств разной степени выраженности у медицинских работников относится длинный рабочий день, высокий риск заражения инфекцией, нехватка средств защиты, одиночество, разлука с семьей и физическая усталость. Были сообщения о том, что ограничение свободы вызывало эпизоды коллективной истерии, ведущей медицинский персонал к отчаянным мерам. Сообщалось о случаях суицида в разных странах, включая Италию, где с разницей в несколько дней две инфицированные медицинские сестры совершили самоубийство. 
У всех остальных групп населения, которые имеют на сегодня постоянный доступ к СМИ, также велик риск развития психоэмоциональных нарушений. 7 февраля в Сингапуре был объявлен оранжевый уровень опасности по COVID-19. В этот же день по всей стране началась повсеместная паническая закупка продуктов питания и гигиенических принадлежностей, что привели к тому, что во многих магазинах в короткие сроки закончились все запасы. Подобная ситуация наблюдалась во многих странах мира.

Таким образом, карантин и другие методы общественного здравоохранения являются эффективными и ценными способами борьбы с инфекционными заболеваниями и общественным беспокойством, но эти меры всегда широко обсуждались, воспринимаясь как навязчивые и сопровождаясь при всех политических режимах подозрением, недоверием и беспорядками. Эти стратегические меры всегда поднимали и продолжают поднимать разнообразные политические, экономические, социальные и этические вопросы. Перед лицом глобального кризиса из-за развития пандемии, часто попирались человеческие права во имя общего блага. Использование сегрегации или изоляции от отдельных лиц, подозреваемых в инфицировании, часто нарушались свободы и здоровых людей, чаще всего из низших классов, а некоторые группы меньшинств подверглись дискриминации. Эта особенность является почти неотъемлемой частью карантина, в которой прослеживается линия преемственности со времен чумы до наших дней. 